\title{
Gastric Necrotic Lesion
}

National Cancer Institute

\section{Source}

National Cancer Institute. Gastric Necrotic Lesion. NCI Thesaurus. Code C78314.

A necrotic process affecting the gastric wall. 